\title{
COMÉRCIO JUSTO E MUDANÇAS CLIMÁTICAS: IDENTIFICANDO PEGADA
} DE CARBONO

\author{
Joana Stelzer*1 \\ Adrielle Betina Inácio Oliveira** \\ Maria Cezilene Araújo de Morais***
}

Resumo: O Comércio Justo representa importante instrumento de sustentabilidade, mas demanda investigações quanto à repercussão na denominada 'pegada de carbono' (contribuição na emissão de gases de efeito estufa). Objetiva-se abordar o Comércio Justo como expressão da relação entre direito e sociedade, especificamente quanto à contribuição gerada como formas alternativas possíveis de viver, ser e produzir. Trata-se de pesquisa teórica, com revisão bibliográfica e sistemática, nos sites Fairtrade International e Periódicos da CAPES. Os resultados indicaram que os produtores da rede são atores ativos na mitigação de emissões de Gases de Efeito Estufa (GEE).

Palavras-chave: Comércio Justo; Pegada de Carbono; Gases de Efeito Estufa; Sustentabilidade; Movimento Social Global

\section{FAIR TRADING AND CLIMATE'S CHANGINGS: IDENTIFYING CARBON'S FOOTPRINT}

\begin{abstract}
Fairtrade portrays such an important sustainable instrument, however, it demands investigations concerning the 'carbon footprint' repercussion (contribution to the emission of greenhouse effect gases). Well as, to approach Fair Trade as an expression related to the relationship between law and society, mainly to the contribution created by a possible being, producing and living ways options. Throughout a theoretical research, with bibliographic and systematic review regarding Fairtrade International and CAPES Periodicals websites. In brief, the results indicated that the network's producers are active actors in mitigating Greenhouse Gas (GHG) Emissions.
\end{abstract}

Keywords: Fair Trade; Carbon footprint; Greenhouse gases; Sustainability; Global social movements

\footnotetext{
1 * Pós-Doutorado pela Faculdade de Direito da Universidade de São Paulo (FADUSP); Doutorado (2003) e Mestrado (1998) em Direito pela Universidade Federal de Santa Catarina. É membro da Sociedade Brasileira de Direito Internacional (SBDI). Coordena o Núcleo de Comércio Justo / Fair Trade, na UFSC. E-mail: joana.stelzer@ufsc.br

** Doutoranda e Mestre em Direito Internacional e Sustentabilidade pelo programa de pós-graduação em Direito (PPGD) da Universidade Federal de Santa Catarina (UFSC). Membro do Grupo de Estudos Avançados em Meio Ambiente e Economia no Direito Internacional (EMAE). E-mail: adriellebetina@gmail.com

*** Doutoranda no programa de pós graduação em Direito (PPGD) da Universidade Federal de Santa Catarina (UFSC). Mestre em Relações Internacionais pela UEPB. Pesquisadora vinculada ao NUPOD - Núcleo para Pesquisa dos Observadores do Direito e Grupo de pesquisa em Direito Internacional Ius Gentium UFSC\CNPQ. E-mail: cezilene@gmail.com
} 


\section{INTRODUÇÃO}

O comércio internacional, em que pesem seus benefícios, também é responsável por manter milhares de trabalhadores em péssimas condições de vida e de trabalho e pela emissão de toneladas de gases de efeito estufa, contribuindo sobremaneira com o efeito estufa aprimorado. Nesse sentido, pegada de carbono pode ser categoria utilizada para se referir à quantidade de carbono, e seus equivalentes, emitida durante o processo produtivo das comodities do Comércio Justo, apresentando-se como métrica de sustentabilidade ambiental da prática.

A pesquisa justifica-se em virtude do Comércio Justo representar expressão da relação entre direito e sociedade, comportando características de movimento social global, circunstância que por si só já é considerado uma mudança do fato social, pois alterou o modo de se relacionar com o produto e com o produtor. Essa alteração do fato social confronta-se com normas jurídicas que não são suficientes para atendê-lo, assim ecoa deste fato social novas normas e, portanto, um novo direito. À luz de tais aspectos emerge a temática que se debruça sobre a possível relação entre o Comércio Justo e a pegada de carbono.

O problema que se impõe, gira em torno da questão: qual contribuição do Comércio Justo na emissão de gases de efeito estufa? A hipótese sustentada é de que pegada de carbono é instrumento potencial dentro do Comércio Justo para demonstrar sustentabilidade ambiental e social das práticas produtivas.

Mudança climática situa-se enquanto fator externo que pressiona qualquer prática produtiva, seja pelos seus efeitos (desertificação, climas extremos etc) ou pela incidência de normas de mitigação das emissões de gases de efeito estufa. O termo apresenta-se como um dos eixos transversais de atuação da CLAC (Coordenadora Latino Americana e do Caribe de Pequenos Agricultores e Trabalhadores do Comércio Justo). Portanto, se há preocupação do Comércio Justo com mudanças climáticas, então a pegada de carbono pode ser potencial instrumento de verificação da sustentabilidade climática da prática produtiva dentro do Comércio Justo.

O objetivo geral deste artigo é elucidar a importância da pegada de carbono nas práticas de Comércio Justo. Para atingir o objetivo geral, estabeleceram-se os seguintes objetivos específicos, compatíveis com as secções do artigo: (a) descrever o Comércio Justo enquanto fenômeno social e jurídico; (b) identificar se o Comércio Justo se relaciona com 
pegada de carbono; e, (c) explicitar as relações entre pegada de carbono e Comércio Justo com base na amostra selecionada.

Os procedimentos metodológicos foram divididos em duas partes. Na primeira tratou-se dos aspectos gerais que tratam da pesquisa teórica, na qual o problema foi abordado de maneira qualitativa, tendo por finalidade descrever o fenômeno jurídico por procedimentos técnicos de revisão bibliográfica, com interpretação sistemática. $\mathrm{Na}$ segunda parte, para atender ao objetivo específico "b" realizou-se busca por assunto nos sites da Fairtrade International (FAIRTRADE, 2020) e dos Periódicos da CAPES (2020), tendo como indexadores "comércio justo", "comercio justo" "fairtrade", "pegada de carbono", "carbon footprint", "huella de carbono" e os operadores boleanos "AND" entre os termos e "OR" em relação ao idioma. Trata-se de pesquisa preambular, não se aprofundando na análise dos documentos, pois o objetivo cinge-se a identificar a existência da relação.

\section{COMÉRCIO JUSTO: O SURGIMENTO DE UM NOVO DIREITO}

As estruturas institucionais do comércio, a Organização Mundial do Comércio (OMC), o Fundo Monetário Internacional (FMI) e o Banco Internacional de Reconstrução e Desenvolvimento (BIRD) como se conhecem, foram pensadas e formuladas ao longo de acontecimentos históricos, sendo que "comércio foi o grande mote do pós-guerra para manter a estabilidade do sistema mundial, juntamente com as finanças". Adiante, demarcam-se alguns desses acontecimentos.

$\mathrm{Na}$ transição do feudalismo para o capitalismo, Stelzer (2018) elenca dois aspectos fundamentais: o primeiro aspecto diz respeito à "venda da capacidade de trabalho", assim os produtos frutos do trabalho não pertence ao trabalhador, mas àquele que compra a energia do trabalho e paga com salário; e, o segundo, foi o renascimento comercial, representado pelas aberturas das rotas comerciais, que intensificando as trocas possibilitou mais lucros, surgindo a necessidade de recursos monetários o que viabilizou um sistema bancário. "A partir desse momento comércio e finanças andariam para sempre de mãos dadas em processo de retroalimentação e intensificando o capitalismo" (STELZER, 2018, p. 24).

Daquele momento em diante alteraram-se valores, o liberalismo "é a expressão e afirmação da sociedade capitalista ocidental" que influenciou o comércio internacional. "Ao se alterarem os valores de uma época também acarretaram consequências no ordenamento jurídico vigente e no que estava por vir". A Revolução Industrial é sinalizada como "um 
marco decisório entre países que tiveram êxito e os ditos fracassados, no plano econômico" (STELZER, 2018). Vale refletir a assertiva de Landes:

A Revolução Industrial fez alguns países mais ricos e outros (relativamente) mais pobres; ou, para sermos mais precisos, alguns países fizeram uma revolução industrial e ficaram mais ricos; e outros não a fizeram e permaneceram pobres. $\mathrm{Na}$ realidade, esse processo de seleção começou muito mais cedo, durante a era dos Descobrimentos (LANDES apud STELZER, 2018, p.25).

O símbolo da Revolução Industrial, a máquina a vapor, foi possível pelo subsídio de mercadores com capital acumulado no comércio triangular de manufatura, escravos e açúcar. Aspectos importantes que moldam a lógica da sociedade atual, foram forjados nesse período. A inventividade e o sistema de fábricas passaram a reger a produção, com a invenção do relógio, passou-se a entender que 'trabalho melhor é trabalho mais rápido'. Marca daquela época e dos dias atuais.

Nessa senda, Stelzer (2018) julgou quatro aspectos determinantes para orquestrar as trocas mundiais até os dias de hoje. O primeiro foi a importância do Padrão Ouro, por meio da utilização do ouro como taxa fixa, ou seja a moeda do país tornava-se equivalente ao ouro e permitia trocas pela mesma quantidade em qualquer outro Estado.

O capitalismo sob as rédeas da ideologia neoliberal "permeava o sistema internacional" que desejava por regras, mas, esses preceitos não poderiam invadir nem disciplinar o mercado. Nessa perspectiva, Harvey (2008) sustenta que essas regras são para conter, limitar, engessar, manipular, restringir a população. O Estado trabalha para o capitalismo, eles se relacionam em plena interdependência, reafirma-se pelas ideias retomadas no neoliberalismo.

Quanto ao terceiro, no início do século XX que o mercado e a economia seriam fatores de fomento para a prosperidade e, talvez, estabilizar a política, permitindo a paz. As conquistas tecnológicas ligadas ao transporte e às comunicações, foram meio essencial para ampliação do comércio internacional (das turbinas a vapor aos refrigeradores). O padrão ouro, o livre comércio e os novos meios de transporte criaram um mercado global conveniente, acessível e previsível.

O quarto fator coaduna o comércio até os dias de hoje: a estreita combinação entre comércio e finanças internacionais. Primeiramente cumpre esclarecer que a Alta finança internacional é uma instituição particular que participou da história do comércio internacional no final do século XIX e no início do século XX exercendo suas atividades até os dias atuais. 
A paz internacional era resultado da posição da organização e técnicas da finança internacional. As finanças como elemento supranacional, sendo prejudicial economicamente a eclosão de uma guerra. "A paz não era obra do acaso, mas do correto entrosamento das finanças, de uma ideia de livre comércio e de financiamento para fazer as trocas internacionais" (STELZER, 2018, p.32).

Todavia, ocorreram crises e recessões econômicas provando que o "liberalismo exterior não evita a recessão econômica e o protecionismo não a provoca" (COMPARATO apud STELZER, 2018). Fatores como desaquecimento econômico, diminuição de exportações, falência de empresas, queda de ações, falência de bancos, dificuldades dos governos interferirem na economia doméstica, revelaram a dificuldade em manter o padrão ouro e atender as demandas dos movimentos trabalhistas.

O comércio externo torna-se fraco até o final da $2^{\circ}$ Guerra, os países se industrializaram quase como uma obrigatoriedade por necessidade. Restava destruída a ordem econômica estabelecida. Do Estado não intervencionista, liberal, migrava-se para um Estado Social. De um laissez-faire à social democracia. O tecido social há muito transformado desde a Revolução Industrial, início da Grande Transformação segundo Polanyi (2012), emergia uma civilização com fundamentos apenas econômicos, com base no lucro. "Passou-se a defender a ganância individual que supostamente beneficiaria toda a sociedade" (STELZER, 2018).

Estabelece-se o padrão dólar-ouro, aceito pelos Estados em razão da possível flexibilidade doméstica para intervenções cambiais, ou seja, os Estados nacionais poderiam desvalorizar suas moedas. $\mathrm{O}$ mundo passa então à hegemonia norte americana, posteriormente confrontada pela formação do bloco europeu, que integrado era grande suficiente para competir.

Após a Segunda Grande Guerra sabia-se ser necessário formar um sistema que contivesse os aspectos econômicos e de gestão da paz, um organismo multilateral mais bem organizado que a Liga das Nações. O cenário foi propício para a criação da Organização das Nações Unidas em 1945, instituição responsável pelo bem-estar coletivo e pelas relações amistosas entre países.

Mas foi antes, em 1944, em Bretton Woods, em New Hampshire, que lideranças de mais de quarenta países se reuniram e organizaram a paz mundial por meio do acordo que criou Fundo Monetário Internacional e o Banco Mundial. Firmado em 1947 a Carta de 
Havana que prometia a criação de uma Organização Internacional do Comércio (OIC), que nunca ocorreu por ausência de aprovação no congresso norte americano. Sendo que, com "os Estados Unidos fora da institucionalização do comércio internacional os demais países não levarão a ideia adiante" (STELZER, 2018, p.47).

Aponta-se como motivos históricos e econômicos que desencadearam a desigualdade e injustiças no comércio internacional: as políticas neoliberais da década de oitenta; a força das corporações e financeirização do comércio; enfraquecimento da soberania dos Estados e por consequência da proteção dos trabalhadores; as mudanças institucionais do pós-Segunda Guerra Mundial (FMI, Banco Mundial); “a criação da Organização Mundial do comércio (OMC) em 1995, consolidou a hegemonia da ortodoxia neoliberal e a visão de livre comércio do desenvolvimento mundial." (MURRAY; RAYNOLDS, 2007, p.7).

Esse sistema multilateral esquematizado do pós Segunda Guerra vem perdendo importância ao longo dos últimos anos, a Organização das Nações Unidas para a Alimentação e a Agricultura (do inglês, Food and Agriculture Organization of the United Nations- FAO) aponta como fatores: o crescente número de acordos bilaterais firmados pelos Estados (20 em 1990, 262 dos dias atuais) e acordos intrarregionais; e, a estrutura de Global Value Chain (cadeias globais de valor), que faz com que o comércio globalizado seja cada vez mais gerido por empresas, que interagem entre si, de forma que a governança Estatal se torna medida auxiliar e não mais principal no processo de produção. Com isso, os fluxos comerciais dessas empresas determinam a balança de importação e exportação dos Estados (STELZER, 2018).

Com base na experiência europeia surge uma segunda fase do Direito, não mais direito internacional público, mas um direito supranacional. E, muito além dessa logicidade e 'acima' do direito supranacional, ainda há uma terceira via, a passagem para o direito Transnacional, na qual se insere o direito do Comércio Justo.

O comércio e a paz seguem como motes para a formação do bloco europeu. Nessa estrutura normativa o próprio direito se reinventa e é utilizado como estratégia. A jurisprudência foi determinante para a integração, e o comércio sedimenta as bases desse processo.

Antes inconcebível e inaceitável, um verdadeiro direito supranacional ganhava a realidade para que o Bloco pudesse existir. Nesse sentido, era o comércio livre entre estados-membros que constituiria a principal realização integracionista, tratava-se do chamado núcleo duro de um bloco de Estados reunidos. Somente a partir da consagração de irrestrito trânsito de mercadorias, outras conquistas poderiam ser sustentadas com mais facilidades. (STELZER, 2018, p.73) 
O Tribunal assumiu um ativismo em prol do avanço comercial da União Europeia que a solução das lides era mais que simplesmente solução de um litígio, com contornos de direito comunitário. "A jurisprudência passou a representar estratégia de articulação comercial, em valor muito além da mera decisão judicial. O direito jurisprudencial passava a possuir valor estratégico" (STELZER, 2018, p.74).

A autora enfatiza que nesse ponto, a supranacionalidade desejava revelar "como o direito teve capacidade de responder às necessidades de uma época.” (STELZER, 2018, p.89). Desse modo, a construir um raciocínio jurídico desse modelo de direito supranacional como uma possibilidade para o Comércio Justo (já na vertente do direito transnacional), ultrapassam-se os limites do direito internacional público, imposto pelo velho modelo pautado pelo direito estatal e pelas instituições internacionais.

\section{COMÉRCIO JUSTO: (RE)CONSTRUÇÃO DE DIREITOS PARA A SUSTENTABILIDADE}

Ocorreram mudanças severas nas relações econômico-jurídicas contemporâneas se comparadas ao século passado. Naquelas circunstâncias, não se cogitava em responsabilidades sobre as desigualdades geradas pela participação dos países nas importações e exportações, ou seja, não há responsáveis pelas injustiças e desigualdades geradas pelo comércio internacional.

O mercado do Comércio Justo diante desse quadro histórico das trocas mundiais,
marcado por egoísmos singulares, deixa de ser uma possibilidade para se converter
em necessidade do capitalismo. O sistema tradicional capitaneado pela OMC
necessita perceber a existência de custos que já não podem mais ser desconsiderados
nas análises econométricas. É imperioso incluir nos cálculos e nas exigências
burocráticas, o custo ambiental, a igualdade de gênero, o prejuízo social, a
erradicação da fome, entre outras necessidades que afligem parte da população
(STELZER, 2018, p.122).

Desta maneira, o Comércio Justo diferencia-se de um modelo de comércio tradicional por atribuir um valor justo a ser pago ao produtor, "evitando que a maior parcela do lucro ficasse nas mãos dos intermediários ou negociante. Buscar-se-iam canais de inserção no comércio mundial para pequenos países." (STELZER, 2018, p.123).

O modelo de comércio tradicional, contemporâneo, é fruto da formação do capitalismo. A autora aponta três pontos principais: (i) as regras do comércio internacional foram forjadas pelos países hegemônicos e em favor desses, que é esboçado pelas regras do sistema GATT/OMC; (ii) pelo domínio de poucas corporações em torno das três áreas da regulamentadas pela OMC- mercadorias (GATT), serviços (GATS) e propriedade intelectual 
(TRIPS); (iii) subsídios governamentais, principalmente nas áreas agrícolas levando "à ruína pequenos produtores de todo o mundo".

Assim, não se pode considerar Comércio Justo como um embate ao modelo tradicional, pois nem chega a ser considerado pelos mainstream que discute o direito do comércio internacional. Todavia, a representatividade que os bens do Comércio Justo têm ganhado é sinalizadora. Van Der Hoff afasta a visão de "ajuda" associada a Comércio Justo como um caminho ao fim da pobreza, uma ideia equivocada porque:

[...] a pobreza é um produto que recai sobre pessoas que se chamam pobres. Primeiro, produzem-se pobres e depois se alivia a pobreza ou se combate. É um mundo ao contrário. A tarefa que consiste em combater um sistema que produz pobreza: organização, mercado diferente, lobby sobre e com as instâncias internacionais, ser parte do movimento de um mundo diferente etc. (VAN DER HOFF apud STELZER, 2018, p.125)

O Comércio Justo contempla uma dimensão além das condições dos produtores, integra outros sujeitos que intervêm na cadeia comercial (exportadores, importadores, transportadores, transformadores, distribuidores, poderes públicos, organizações sindicais etc.). "Trata-se, portanto, do restabelecimento de relações saudáveis entre produtores e consumidores, ou seja, um retorno à aquisição de mercadorias pautadas pela necessidade, equidade, confiança e solidariedade." (STELZER, 2018, p. 127).

Existem duas versões basilares do Comércio Justo, uma primeira versão ligada aos anseios dos consumidores da Europa que queriam "ficar de consciência limpa ao consumir", um certo assistencialismo (Fair Trade); e, outra, partindo dos próprios produtores latinoamericanos em busca de melhores condições de vida.

Frisa-se que o Comércio Justo seria uma nova forma de comercializar e uma maneira de provocar mudanças no comércio internacional convencional, são diversos movimentos, comportando uma vasta gama atuações, o que dificultaria uma definição (STELZER, 2018, p.132).

Murray e Raynolds definem como Comércio Justo um conjunto de movimentos surgidos nas últimas décadas, o texto enfatiza que o movimento não tem objetivo de ser um movimento antiglobalização, mas que deseja utilizar-se da globalização e seus benefícios sistêmicos para propiciar uma mudança no modelo de comércio. "Esforços como o movimento anti-exploração de roupas, rotulagem ecológica em madeira e certificação de Comércio Justo em produtos alimentícios buscam criar um futuro mais sustentável e socialmente justo.” (MURRAY; RAYNOLDS, 2007, p. 4). 
O Comércio Justo é melhor entendido como uma resposta emergente aos efeitos negativos da globalização contemporânea, e particularmente à natureza muitas vezes injusta e não equitativa do comércio internacional contemporâneo. Como tal, não é um movimento de "antiglobalização", mas, em vez disso, faz parte do que descrevemos como uma "nova globalização", sendo desenvolvida através de redes contra-hegemônicas (Evans, 2005) buscando uma estratégia de reenquadrar a globalização a partir de baixo (Falk, 1997) (MURRAY; RAYNOLDS, 2007, p.6).

O movimento tem início desde a década de 1940 com uma série de iniciativas norteamericanas e europeias que buscam auxiliar grupos desfavorecidos através da criação de redes comerciais alternativas. Os autores apresentam ao longo da seção as construções do movimento, desde a diferenciação do movimento inicial a um novo modelo de movimento surgido no final da década de oitenta pela introdução do certificado de rotulagem, e, também como os processos ocorreram de forma diferente em cada região ou Estado-nação. "Desde 1998, os principais grupos de ATO e rotulagem têm trabalhado para encontrar um terreno comum e buscar interesses conjuntos através de uma aliança informal chamada FINE, uma sigla composta da primeira letra dos nomes dos membros: FLO, IFAT, NEWS! e EFTA.

A FINE procura promover as atividades dos membros compartilhando informações, harmonizando as diretrizes do Comércio Justo e mantendo um Escritório Conjunto de Defesa do Comércio Justo em Bruxelas. FINE (2003) é um grupo de trabalho sem poder de decisão, desenvolveu uma definição comum de Comércio Justo, que é referenciada em todo o movimento.

O Comércio Justo é uma parceria comercial, baseada no diálogo, na transparência e no respeito, que busca maior equidade no comércio internacional. Contribui para o desenvolvimento sustentável, oferecendo melhores condições comerciais e garantindo os direitos dos produtores e trabalhadores marginalizados especialmente no sul. (RAYNOLDS; LONG, 2007, p.17-18)

O Comércio Justo, portanto, tem dois objetivos: “(1) fomentar a comércio igualitário entre consumidores do Norte e produtores do Sul (2) fazer campanha por mudanças nas práticas comerciais tradicionais (desiguais)" (RAYNOLDS; LONG, 2007). O texto segue discorrendo sobre a atuação das instituições ao longo do tempo, e como o crescimento das dimensões do Fair Trade tem feito que empresas grandes passassem a se interessar pela rotulagem ou fazer parte da rede.

Em que pese seja complicado fazer comparações detalhadas, pela escassez de dados, verifica-se o crescimento do mercado justo. "O mercado mundial total de Comércio Justo, incluindo ATO e produtos rotulados, está avaliado em US\$ 1,6 bilhão.” (RAYNOLDS; LONG, 2007, p.20). Por mais que esse valor não seja significativo diante do comércio internacional os autores ressaltam: 
As vendas de volumes de produtos certificados pelo Comércio Justo aumentaram $483 \%$ entre 1998 e 2005; 23 por cento entre 2004 e 2005. [...] Quantificar o crescimento em empreendimentos de ATO mais dispersos é difícil, mas é claramente mais modesto. A Europa mantém sua proeminência histórica nos mercados ATO e Fair Trade, com o Reino Unido na liderança, com US \$ 345 milhões em vendas certificadas pela FLO e US \$ 7,5 milhões em vendas da ATO. No entanto, são os Estados Unidos que agora têm o maior mercado nacional de comércio justo, com cerca de US \$ 428 milhões em vendas certificadas e US \$ 80 milhões em vendas de ATO. (RAYNOLDS; LONG, 2007, p.21).

É interessante salientar a maior representatividade de produtos alimentícios, inicialmente com café e banana sendo agora ampliado a alimentos em geral com foco em orgânicos, esse comportamento dos compradores além de representar uma preocupação com justiça social do comércio é uma ação de negação ao modelo tradicional de agricultura em escala.

Os maiores consumidores localizam-se na Europa, Reino Unido, Suíça, Países Baixos, Alemanha, França, Itália; América do Norte, EUA, Canadá; e, Pacífico, Japão. As principais commodities são: café, chá, cacau, açúcar, bananas frescas.

A rotulagem é apontada como item importante no processo de expansão geográfica dos produtos do Comércio Justo.

\begin{abstract}
Os grupos de produtores certificados pela FLO dobraram de 211 para 433 entre 1988 e 2004. Os projetos do Plano Estratégico da FLO continuaram em rápido crescimento: 650 grupos, 30 commodities certificadas e 210.000 toneladas de commodities certificadas são esperadas para 2008. Centenas de milhares de produtores e trabalhadores de pequena escala em todo o mundo estão agora produzindo itens certificados do Comércio Justo e seus números parecem prontos para aumentar (RAYNOLDS; LONG, 2007, p.25).
\end{abstract}

A América Latina tem grande representatividade, "representa o centro do comércio justo certificado de produção", "produz $83 \%$ de todo o café certificado pela Fair Trade, 98\% de todas as bananas, $48 \%$ de todo o cacau e $68 \%$ de todo o açúcar. Exportando para os países compradores de commodities certificadas de produtos como café, banana, cacau, chá, açúcar e outras frutas e sucos: "O café é, de longe, a principal exportação de Comércio Justo da região, gerando US\$ 61 milhões, seguido pela banana que gera US\$ 21 milhões por ano" (RAYNOLDS; LONG, 2007, p.25).

A tensão Norte e Sul é levada em conta pelo movimento Fair Trade, que olha para as desigualdades nessa relação, bem como apresenta caminhos para que esses trabalhadores do Sul global se coloquem no comércio globalizado de forma justa.

A proposta latino-americana de Comércio Justo emergiu com a CLAC (Coordenadora Latino Americana e do Caribe de Pequenos Agricultores e Trabalhadores do Comércio Justo). A instituição nasce em 2004, em um evento na cidade de Oaxaca, México, 
essa iniciativa é apontada como resposta as contradições apresentadas pela FLO (Fairtrade International).

Em seu marco histórico, a CLAC é importante. Segundo Stelzer (2018), a diferenciação do movimento do comércio justo do norte e do sul exalta a sustentabilidade cultural, "existe um mínimo axiológico no Comércio Justo latino-americano. A vertente cultural pulsa sob o manto da sustentabilidade integral do ser humano, no que distingue do sistema FLO” (STELZER, 2018, p.140).

O Comércio Justo pode ser visto em três campos de negociações e que seriam primordiais de olhar a partir da perspectiva histórica: (i) a promoção e estruturação de uma política de redes; (ii) o crescente interesse do consumidor em reforçar as condições éticas e ambientais da produção de alimentos, mas é simultaneamente associado à incorporação do Comércio Justo nos setores corporativos e de varejo convencionais (no âmbito da política do consumo); e, (iii) política de produção, com o aumento da produção denota-se a necessidade de ampliação da participação geográfica, de commodities e empresas, "o que está corroendo a base histórica de pequenos agricultores do movimento, embora possa ampliar a distribuição potencial de benefícios" (RAYNOLDS; LONG, 2007, p.29).

Mesmo diante dos desafios e contradições entre a abordagem do Fair Trade e do Comércio Justo, e ainda mais neste cenário crítico no qual se vive em razão da pandemia do Corona-Vírus, o Comércio Justo se apresenta como opção plural a um futuro da vida em sociedade (inclusive quanto ao uso do Prêmio Fairtrade, recentemente com critérios flexibilizados).

Ademais, a relação entre mudanças climáticas e Comércio Justo tem atenção da instituição que incluiu esse tema como um dos eixos transversais de atuação da CLAC (Coordenadora Latino Americana e do Caribe de Pequenos Agricultores e Trabalhadores do Comércio Justo), juntamente com Gênero, Inclusão de Jovens, Proteção Infantil, Soberania Alimentar, boas práticas trabalhistas e Sustentabilidade Ambiental. Portanto, se há preocupação com mudanças climáticas, a pegada de carbono pode ser potencial instrumento de verificação da sustentabilidade climática da prática produtiva.

\section{PEGADA DE CARBONO NO COMÉRCIO JUSTO}

Pegada de Carbono é termo que contempla uma gama extensa de significados, podese referir à Avaliação Ciclo de Vida - AVC (Life Cycle Assessment- LCA), ao Potencial de Aquecimento Global (PAG) (Global Warming Potential -GWP), à Pegada de Carbono de 
Produtos (Carbon Footprint of Products - CFP) e ainda a situações mais genéricas. Contudo, em todas as conceituações a finalidade do termo é expressar uma métrica para expressar a pressão de determinada prática sobre o sistema climático (OLIVEIRA, 2020).

A denominada 'alteração(ões) no sistema climático' nesta pesquisa apresenta-se como sinônimo de mudanças climáticas, termo que se refere às mudanças na totalidade de atributos que definem o clima. Contempla desde o aquecimento global, fenômeno do aumento da temperatura média da superfície terrestre nos últimos dois séculos, aos padrões de precipitação, ventos, correntes oceânicas e outras medidas do clima da Terra. Mudanças essas relacionadas a dois componentes: um de origem natural, variabilidade climática passada e atual; e, outra, de origem humana, compatível com o período industrial dos últimos dois séculos.

Essas últimas, de origem antropogênica, são corriqueiramente utilizadas como sinônimo de aquecimento global. As mudanças nas temperaturas da superfície da Terra, inclui a noção de balanço energético (como o sistema climático funciona) e de efeito estufa, em especial o caso aprimorado (ou humano), e os chamados feedbacks, situações que podem ampliar a magnitude das mudanças climáticas.

A existência de efeito estufa é incontroversa, são gases que absorvem a energia emitida pela Terra e reemitem em qualquer direção, tanto para a superfície terrestre como para a atmosfera, num processo de retenção e reemissão de energia. Em busca da manutenção do equilíbrio, a Terra deve, portanto, emitir mais do que as 70 unidades originais de radiação, o que, por sua vez, leva ao aquecimento da atmosfera mais baixa. No entanto esse efeito estufa natural, essencial para a vida na Terra, porque mantém a temperatura média em $15^{\circ} \mathrm{C}$, está sendo aprimorado. O efeito estufa aprimorado significa dizer que todos os outros elementos permanecem iguais, porém com a maior concentração de gases de efeito estufa na atmosfera, retendo mais calor e elevando a temperatura na superfície da Terra (MANN, 2009).

Essa alteração do balanço energético, por influência antropogênica, deve-se primeiramente, à queima de combustíveis fósseis e outras práticas industriais, agrícolas ou de uso da terra. Essas práticas emitem tanto os tradicionais gases de efeito estufa, Dióxido de Carbono $\left(\mathrm{CO}_{2}\right)$, Metano $\left(\mathrm{CH}_{4}\right)$ e Oxido Nitroso $\left(\mathrm{N}_{2} \mathrm{O}\right)$, como outros gases que são altamente potenciais de aquecimento global, Clorofluorocarbonetos (CFCs) Hidrofluorcarbonetos (HFCs), Perofluorocarbonetos (PFCs), entre outros. 
Nesta senda, pegada de carbono é instrumento que visa elucidar quanto determinadas práticas, em determinado espaço de tempo e local (inputs, processo de beneficiamento, outputs, resíduos), emitem de gases de efeito estufa (utilizando carbono equivalente ${ }^{2}$ ).

Dito isto, apresenta-se o conceito de pegada de carbono. A categoria conceitual Avaliação Ciclo de Vida - AVC ou Life Cycle Assessment- LCA refere-se a estrutura metodológica dada pela International Organization for Standardization (ISO), no Brasil é normatizada nos documentos similares aos da ISO pela ABNT NBR ISO 14040:2009, apresenta os princípios e estrutura, e ABNT NBR ISO 14044:2009, apresenta requisitos e orientações. A ABNT define que avaliação do ciclo de vida "estuda os aspectos ambientais e os impactos potenciais ao longo da vida de um produto (isto é, do "berço ao túmulo"), desde a aquisição da matéria-prima, passando por produção, uso e disposição final.” (ABNT, 2001, p.2)

A Avaliação do Ciclo de Vida consiste em "uma das várias técnicas de gestão ambiental, por exemplo, avaliação de risco, avaliação de desempenho ambiental, auditoria ambiental e avaliação de impacto ambiental, e pode não ser a técnica mais apropriada a ser empregada em todas as situações." (ABNT, 2001). São categorias de impacto inclusas na avaliação do ciclo de vida (ACV): impactos ambientais que necessitam ser consideradas, uso de recursos, a saúde humana e as consequências ecológicas. A avaliação do ciclo de vida deve incluir a definição de objetivo e escopo, análise de inventário, avaliação de impactos e interpretação de resultados. Essas são as fases determinadas pela ISO, levando em consideração que o inventário é determinado pelo pesquisador, pode-se ter escopo diferentes categorias de impactos ambientais, a ACV não aborda os aspectos econômicos ou sociais de um produto (ABNT, 2001, p.6-7).

Pegada de Carbono de Produtos ou Carbon Footprint of Products - CFP refere-se a ISO 14067:2018, por sua vez, analisa, apenas, uma única categoria de impacto: mudança climática. Não avalia aspectos ou impactos sociais ou econômicos, ou quaisquer outros aspectos ambientais e impactos relacionados potencialmente decorrentes do ciclo de vida de um produto. A ACV especifica princípios, requisitos e diretrizes para a quantificação e geração de relatórios da pegada de carbono de um produto (CFP), de maneira consistente com as normas internacionais de avaliação do ciclo de vida (do inglês Life Cycle Assessment- LCA

\footnotetext{
${ }^{2}$ Equivalente de dióxido de carbono (CO2eq) é a métrica que converte os demais gases de efeito estufa em CO2. Por exemplo, o potencial de aquecimento global do gás metano é 21 vezes maior do que o potencial do CO2. Então, dizemos que o CO2 equivalente do metano é igual a 21 (IPAM, 2010, p.32).
} 
) (ISO 14040 e ISO 14044); também, são especificados requisitos e diretrizes para a quantificação de uma CFP parcial (ISO 2018, p.5).

Pegada de Carbono de um produto é soma das emissões de gases de efeito estufa e remoções desses em um sistema de produtos expressas em equivalentes de $\mathrm{CO}_{2}$ e com base em uma avaliação do ciclo de vida (ACV) usando o método único da categoria de impacto das mudanças climáticas. Enquanto, a Pegada de Carbono Parcial de um Produto é soma das emissões de GEE (gases do efeito estufa) e remoções de GEE de um ou mais processos selecionados em um sistema de produtos, expressos em equivalentes de $\mathrm{CO}_{2}$ e com base nas etapas ou processos selecionados no ciclo de vida (ISO, 2018).

Por fim, pegada de carbono como Potencial de Aquecimento Global (PAG) ou Global Warming Potential (GWP) consiste em um indicador de critério de avaliação ambiental, método estabelecido pelo Guidelines for National Greenhouse Gas Inventories de 2006 do Painel Intergovernamental sobre Mudanças Climáticas, desde então vem sendo revisado e atualizado, consiste na contabilização do total de emissões de $\mathrm{CO}_{2}$ e seus equivalentes, montando modelos climáticos expressados para sistemas definidos de períodos curtos, 20 anos, ou longos 100, 500 anos.

\section{COMÉRCIO JUSTO E PEGADA DE CARBONO: VERIFICAÇÃO BILIOMÉTRICA}

Para atender ao objetivo específico “(b) identificar se comércio justo se relaciona com pegada de carbono" realizou-se busca por assunto nos sites da Fairtrade International e site de Periódicos da CAPES, tendo como indexadores "comércio justo", "Comercio Justo", "fairtrade", "pegada de carbono", “carbon footprint", "huella de carbono" e os operadores boleanos “AND” entre os termos e "OR” em relação ao idioma.

No portal de periódicos da Capes delimitando a busca por assunto (termo exato) foram encontrados três artigos. Na fase de leitura dos textos, um artigo foi excluído por não apresentar o termo Fair Trade no texto. No site Fairtrade International, foi desnecessário incluir o termo 'fairtrade and carbono footprint', a página apresentava erro, buscando apenas por 'carbono footprint' foram encontrados onze resultados.

Como método de interpretação utilizou-se de método gramatical. Sistematizando as informações, foram lidos os resumos dos artigos e introdução da consultoria Life Cycle Assessment Cut Roses, e os textos completos das notícias. Em relação aos resultados encontrados, segue síntese dos achados. 
Quadro 1: Resultados da busca sobre Comércio Justo e Pegada de Carbono

\begin{tabular}{|c|c|c|c|}
\hline $\mathbf{Q t}$ & $\begin{array}{l}\text { AUTOR } \\
\end{array}$ & $\begin{array}{c}\text { TÍTULO } \\
\end{array}$ & \begin{tabular}{|l} 
LOCAL \\
\end{tabular} \\
\hline 1 & $\begin{array}{l}\text { Faical Akaichi, } \\
\text { Steven de Grauw } \\
\text { and Paul Darmon }\end{array}$ & $\begin{array}{l}\text { Are Fair Trade, Carbon } \\
\text { Footprint and Organic } \\
\text { Attributes competing? Some } \\
\text { Evidences from Scotland, } \\
\text { Netherland and France } \\
\end{array}$ & $\begin{array}{l}\text { International Association of } \\
\text { Agricultural Economists (IAAE) > } \\
2015 \text { Conference, August 9-14, 2015, } \\
\text { Milan, Italy }\end{array}$ \\
\hline 2 & $\begin{array}{l}\text { H.A. Hassard, M.H. } \\
\text { Couch, T. Techa- } \\
\text { erawan, B.C. } \\
\text { McLellan }\end{array}$ & $\begin{array}{l}\text { Product carbon footprint and } \\
\text { energy analysis of alternative } \\
\text { coffee products in Japan }{ }^{3}\end{array}$ & $\begin{array}{l}\text { Journal of Cleaner Production } 73 \\
\text { (2014) 310e321 }\end{array}$ \\
\hline 3 & $\begin{array}{l}\text { Adolf A. Acquaye, } \\
\text { Fred A. Yamoah, } \\
\text { Kuishuang Feng }\end{array}$ & $\begin{array}{l}\text { An integrated environmental } \\
\text { and fairtrade labelling scheme } \\
\text { for product supply chains }\end{array}$ & $\begin{array}{l}\text { Int. J. Production Economics } 164 \\
\text { (2015) 472-483 }\end{array}$ \\
\hline 4 & $\begin{array}{l}\text { Fairtrade } \\
\text { International News } \\
\text { Articles } 6 \text { Dec } 2019\end{array}$ & $\begin{array}{l}\text { Protecting Producers From the } \\
\text { Climate Crisis: A Priority For } \\
\text { Fairtrade }\end{array}$ & https://www.fairtrade.net \\
\hline 5 & $\begin{array}{l}\text { Fairtrade } \\
\text { International } \\
\text { Library } \\
12 \text { Feb } 2019 \\
\text { Martina Alig }\end{array}$ & $\begin{array}{l}\text { Life Cycle Assessment Cut } \\
\text { Roses }\end{array}$ & https://www.fairtrade.net \\
\hline 6 & $\begin{array}{l}\text { Fairtrade } \\
\text { International } \\
\text { Key Issues }\end{array}$ & Climate Change & https://www.fairtrade.net \\
\hline 7 & $\begin{array}{l}\text { Fairtrade } \\
\text { International } \\
\text { Key Issues SDGs }\end{array}$ & SDG13: Climate Action & https://www.fairtrade.net \\
\hline 8 & $\begin{array}{l}\text { Fairtrade } \\
\text { International } \\
\text { News Articles } \\
13 \text { Jan } 2017 \\
\end{array}$ & $\begin{array}{l}\text { First Climate Project Certified } \\
\text { Under Fairtrade Climate } \\
\text { Standard }\end{array}$ & https://www.fairtrade.net \\
\hline 9 & $\begin{array}{l}\text { Fairtrade } \\
\text { International } \\
\text { News Articles } \\
24 \text { Sep } 2020\end{array}$ & $\begin{array}{l}\text { Amazon's New 'Climate Pledge } \\
\text { Friendly' Programme Helps } \\
\text { Fairtrade Consumers To } \\
\text { Choose The World They Want }\end{array}$ & https://www.fairtrade.net \\
\hline 10 & $\begin{array}{l}\text { Fairtrade } \\
\text { International } \\
\text { News Articles } \\
14 \text { Feb } 2019\end{array}$ & $\begin{array}{l}\text { Give Some Love To The Planet } \\
\text { This Valentine's Day }\end{array}$ & https://www.fairtrade.net \\
\hline 11 & $\begin{array}{l}\text { Fairtrade } \\
\text { International } \\
\text { News Articles } \\
5 \text { Nov } 2017\end{array}$ & $\begin{array}{l}\text { Fiji's Fairtrade Sugar } \\
\text { Farmers Urge Action On } \\
\text { Climate Change }\end{array}$ & https://www.fairtrade.net \\
\hline 12 & $\begin{array}{l}\text { Fairtrade } \\
\text { International } \\
\text { Key Issues SDGs }\end{array}$ & SDG2: Zero Hunger & https://www.fairtrade.net \\
\hline
\end{tabular}

\footnotetext{
${ }^{3}$ Artigo excluído da análise porque apresentava fair trade apenas nas referências.
} 


\begin{tabular}{|c|l|l|l|}
\hline 13 & $\begin{array}{l}\text { Fairtrade } \\
\text { International } \\
\text { Fairtrade Products }\end{array}$ & Flowers And Plants & https://www.fairtrade.net \\
\hline 14 & $\begin{array}{l}\text { Fairtrade } \\
\text { International } \\
\text { News Articles 7 Nov } \\
2017\end{array}$ & $\begin{array}{l}\text { Fiji Sugar Farmers Adapt To } \\
\text { Survive }\end{array}$ & https://www.fairtrade.net \\
\hline
\end{tabular}

Fonte: Dados primários

Dos resultados encontrados no site da Fairtrade International seis são classificados como News Articles, três como Key Issues, sendo dois específicos do Objetivos de Desenvolvimento Sustentável (Sustainable Development Goals - SDGs), um fairtrade products e um em library.

O único documento encontrado no site Fairtrade International que apresenta números e o impacto real do modo de produção Comércio Justo nas emissões de gases e efeito estufa foi o Life Cycle Assessment Cut Roses ${ }^{4}$, encontrado na categoria biblioteca. Trata-se de uma consultoria executada pela empresa Treeze Ltd. Chama atenção a atenção a definição que a empresa apresenta de si no relatório, expressando compromisso com emissão zero:

[...] A equipe é especializada na avaliação do ciclo de vida e sua aplicação no desenvolvimento de produtos, gestão ambiental de empresas e organizações, formulação de políticas, treinamento e pesquisa. O serviço é caracterizado pela justiça, excelência e independência. Treeze "simboliza as árvores de processo dentro da modelagem Life Cycle Assessment -LCA. O nome significa, em direção à eficiência de recursos e energia e emissões zero" objetivos para os quais a LCA pode contribuir significativamente. (ALIG; FRISCHKNECHT, 2018, p.32)

O estudo determina os impactos ambientais da produção de flores, especificamente de cinco rosas de cortes diferentes: rosas convencionais do Equador, rosas médias e Fairtrade do Quênia e rosas convencionais e rosas de produção otimizada da Holanda. Considera desde a produção agrícola no país de origem, o acondicionamento das rosas e seu transporte para a Suíça e destino final, ou seja, todo o ciclo de vida. O estudo é uma revisão que cruza dados de pesquisas já realizadas.

O documento é potencial para ser aplicado em outras consultorias, com as devidas adaptações ao produto analisado, mas pode ser modelo para análise e comparativos de ciclos de vida de diversos produtos em pequenas produções. Além da emissão de gases de efeito estufa tem como fatores, pegada hídrica, demanda cumulativa de energia e perda de

\footnotetext{
${ }^{4}$ Não apresenta termo pegada de carbono e sim emissões de gases de efeito estufa, infere-se que foi incluído nos resultados porque apresenta pegada hídrica, logo por não ter buscado o termo exato (pelo uso de aspas) foi incluso.
} 
biodiversidade, eutrofização terrestre, eutrofização aquática, uso de pesticidas. A pesquisa conclui que "é possível afirmar que os padrões do Comércio Justo não apenas aumentam a justiça social, mas também podem contribuir para a redução dos impactos ambientais da produção de rosas." (ALIG; FRISCHKNECHT, 2018).

Em relação aos outros materiais encontrados no site da Fairtrade International podese resumir o uso do termo pegada de carbono por dois caminhos: dos produtores como aqueles com menor pegada de carbono e como mais afetados. Além disto, a instituição expressa seu papel e nichos de atuação na proteção dos produtores na crise climática e sua capacitação para resiliência e mitigação de suas emissões.

Quanto aos artigos científicos encontrados da busca no site de Periódicos da Capes, um apresenta um estudo de casos múltiplos realizado na Escócia, Holanda e França com s seguinte finalidade:

Avaliar se os consumidores têm preferências e disposição a pagar (willingness to pay -WTP) por atributos éticos (ou seja, comércio justo, orgânico, baixa pegada de carbono) de bananas e para descobrir se os atributos éticos desse alimento estão competindo na realidade mercados [...] (AKAICHI et al., 2015).

É interessante notar que, neste estudo, pegada de carbono aparece como um dos atributos éticos de análise de preferência de consumo. E, que um dos resultados obtidos, os consumidores estão dispostos a pagar mais pelo atributo das bananas rotuladas com menor pegada de carbono.

Por fim, o último resumo analisado do artigo An integrated environmental and fairtrade labelling scheme (Um esquema integrado de rotulagem ambiental e Comércio Justo) é extremamente congruente com a proposta desta pesquisa. No resumo do artigo os autores delimitam a rotulagem de carbono, sustentam que o artigo "apresenta um processo sistemático de desenvolvimento de uma estrutura de rotulagem ambiental como uma extensão da rotulagem de carbono, usando a certificação de comércio justo como uma plataforma para facilitar o processo.”. Os autores baseiam o processo de rotulagem ambiental em dois princípios: O Princípio Quantitativo na Rotulagem Ecológica e o Princípio da Perspectiva do Ciclo de Vida Completo (ACQUAYE et al., 2015).

Os pesquisadores advertem que as rotulagens de carbono se apresentam como forma de impulsionar o alcance de sistemas de produção sustentáveis de cadeias de abastecimento de produtos.

[...] especificamente neste artigo para a cadeia de suprimentos do Reino UnidoÍndia-Resto do Mundo. [...] comunicar os impactos ambientais aos parceiros da cadeia de abastecimento fornece um suporte à decisão para tomar ações para reduzir 
os impactos gerais, identificando os processos dentro da cadeia de abastecimento global que precisam de priorização (ACQUAYE et al., 2015).

Este artigo demostrou-se elucidativo da potencialidade da pegada de carbono (como rótulo) como instrumento de horizontalidade para informar dois grupos principais de partes interessadas na cadeia de abastecimento: consumidores e parceiros da cadeia de abastecimento (ACQUAYE et al., 2015). Verifica-se, portanto, que a partir das bases de dados investigadas, a discussão envolvendo Comércio Justo e Pegada de Carbono é relevante, embora se encontre em estágio inicial o que sugere pesquisas correlatas.

\section{CONSIDERAÇÕES FINAIS}

O presente estudo propôs-se a discutir qual contribuição do Comércio Justo na emissão de gases de efeito estufa, a partir da propositura que a pegada de carbono é instrumento potencial dentro desse emergente fenômeno mercantil para demonstrar sustentabilidade ambiental e social das práticas produtivas.

Enquanto fenômeno social e jurídico, o Comércio Justo materializa a necessidade latente de conexão entre consumidor e produtor, retoma a consciência e humanidade nos atos de consumo e atua como movimento social global, tudo com ação política e social, com princípios e objetivos. Dessa maneira, constitui-se como propostas possíveis, plurais, justas e equânime, especialmente quando comparado ao denominado free trade (o comércio tradicional capitaneado pela OMC).

A novel proposta comercial correlaciona-se com mudança climática, promovendo respeito perante inúmeros aspectos da crise climática. A considerar que o foco do artigo era identificar se há práticas que envolvem o Comércio Justo e sua relação com pegada de carbono, delimitou-se a pesquisa no site da Fairtrade International e dos Periódicos da CAPES. Enquanto o primeiro representa a abordagem que o próprio Comércio Justo destina à pegada de carbono, o Portal de Periódicos simboliza aproximações em pesquisas científicas.

No site da Fairtrade International foi possível evidenciar as relações entre pegada de carbono e Comércio Justo. Com efeito, nas abas sobre notícias, destinam-se a explicitar os desafios que os produtores passam em razão da crise climática, tendo eles pegadas de carbono baixas, mas também como oportunidade de resiliência por aplicarem cada vez mais práticas produtivas com menor emissão de gases de efeito estufa.

Na aba biblioteca, no site da Fairtrade International, por sua vez, constatou-se uma consultoria que apresenta dados robustos e comparativos sobre a prática de colheita de flores 
(rosas). O estudo cruzou dados sobre pegada hídrica, emissões de gases de efeito estufa, perda de biodiversidade, avaliando o ciclo de vida completo dessas commodities. Por fim, apresentou-se uma sugestão para que as práticas sejam cada vez mais sustentáveis.

Os artigos resultados da busca no Periódicos Capes apresentaram cenários interessantes. Entre os achados, uma investigação destacou-se por ser a pegada de carbono um dos atributos éticos que influenciam a disposição do consumidor em pagar pelo produto. Enquanto, o outro, trouxe a rotulagem ecológica, em especial rótulo da pegada de carbono, como meio de expressar os impactos ambientais aos parceiros comerciais e aos consumidores, sendo o modelo jurídico do Comércio Justo identificado como facilitador para este processo. Com isso, considera-se corroborada a hipótese apresentada. Por fim, é possível inferir que este estudo sugere pesquisas futuras, pois o fenômeno jurídico-social expressa evidentes correlações entre Comércio Justo e Pegada de Carbono necessitando de abordagens multidisciplinares.

\section{REFERÊNCIAS}

ACQUAYE, Adolf A.; YAMOAH, Fred A.; FENG, Kuishuang. An integrated environmental and fairtrade labelling scheme for product supply chains. Int. J. Production Economics 164 (2015) 472-483. http://dx.doi.org/10.1016/j.ijpe.2014.12.014

AKAICHI, Faical; GRAUW, Steven de; DARMON, Paul. Are Fair Trade, Carbon Footprint and Organic Attributes competing? Some Evidences from Scotland, Netherland and France. International Association of Agricultural Economists (IAAE)

ALIG, Martina; FRISCHKNECHT, Rolf. Life Cycle Assessment Cut Roses. Treeze Ltd., fair life cycle thinking. Uster: Suíça, 2018.

ASSOCIAÇÃO BRASILEIRA DE NORMAS TÉCNICAS - ABNT. NBR ISO 14040: gestão ambiental, avaliação do ciclo de vida, princípios e estruturas. Rio de Janeiro, 2001.

CAPES (Coordenação de Aperfeiçoamento de Pessoal de Nível Superior). Periódicos Capes. Disponível em: https://www.periodicos.capes.gov.br/ Acesso em: 25 set. 2020.

FAIRTRADE (Fairtrade International). Fairtrade News. Disponível em: https://www.fairtrade.net/ Acesso em: 25 set. 2020

HARVEY, David. Neoliberalismo: histórias e implicações. (Título original: A brief history of neoliberalismo was originally). São Paulo: Edições Loyola, 2008.

MANN, Michael E. Do global warming and climate change represent a serious threat to our welfare and environment? Social Philosophy and Policy, 26(02), 193. 2009. Doi:10.1017/s0265052509090220 
MIGNOLO, Walter. The Darker Side Of Western Modernity: Global Futures, Decolonial Options. Durham \& London: Duke University Press, 2011.

MURRAY, Douglas L.; RAYNOLDS, Laura T. Globalization and its antinomies: Negotiating a Fair Trade movement. In: RAYNOLDS, Laura T, et al . Fair Trade: the challenges of transforming globalization. Londres, Reino Unido: Routledge, 2007. 235 p.

OLIVEIRA, Adrielle Betina I.. Mudanças Climáticas e Organização Mundial do Comércio: pegada de carbono como instrumento jurídico-econômico de efetivação do objetivo de contenção da temperatura global do Acordo de Paris. Dissertação (Mestrado em direito)- Programa de pós-graduação em direito da Universidade Federal de Santa Catarina, Florianópolis/SC, p.190, 2020.

RAYNOLDS, Laura T; LONG, Michael A.. Fair/Alternative Trade Historical and empirical dimensions. In RAYNOLDS, Laura T, et al . Fair Trade: the challenges of transforming globalization. Londres, Reino Unido: Routledge, 2007. 235 p.

STELZER, Joana. Direito do Comércio Internacional: do free trade ao fair trade. Curitiba: Juruá, 2018. 216 p. 